\title{
EVALUATION AND OPTIMIZATION OF ELECTRICAL SUBMERSIBLE PUMPS THAT CONTAIN HIGH PI USING VARIABLE SPEED DRIVE WITH A FREQUENCY ABOVE 60HZ ON WELL "X" IN FIELD "Y" \\ (EVALUASI DAN OPTIMISASI SUMUR ELECTRICAL SUBMERSIBLE PUMP YANG MEMILIKI PI TINGGI DENGAN MENGGUNAKAN VARIABLE SPEED DRIVE DENGAN FREKUENSI DIATAS 6OHZ PADA SUMUR " $\mathrm{X}^{\prime \prime}$ LAPANGAN "Y")
}

\author{
Richa Melysa $^{1 *}$, Dike Fitriansyah Putra ${ }^{1}$, Dedek Julianto ${ }^{1}$, Dody Yulianto ${ }^{2}$, Masli Irwan \\ Rosli $^{3}$ \\ ${ }^{1}$ Jurusan Teknik Perminyakan, Fakultas Teknik, Universitas Islam Riau \\ ${ }^{2}$ Program Studi Teknik Mesin Fakultas Teknik Universitas Islam Riau \\ ${ }^{3}$ Department of Chemical \& Process Engineering Faculty of Engineering and Built \\ *corresponding author : richamelysa@eng.uir.ac.id
}

\begin{abstract}
A well that is in a constant state of production will cause reservoir pressure to fall, and the flow rate will go down as well, resulting in a decrease in the productivity of the well. For this reason, there is a need for energy that can help lift fluid up to the surface. In the primary method there are 2 stages of production, namely "natural flow" where oil is raised directly through the tubing surface, and "artificial lift" which is the method of obtaining oil by utilizing the aid of additional tools. In the oil industry there are various types of artificial lifts, one of which is an Electric Submersible Pump (ESP). An Electric Submersible Pump is an electric pump that is immersed into a liquid. This pump is made on the basis of a multilevel centrifugal pump where each level has an impeller and diffuser which aims to push the fluid to the surface. ESP planning is strongly influenced by the productivity of production wells. The rate of fluid production influences the selection of pump type and size. This is because each pump has its own production rate based on the type and size of each pump used. In the course of producing oil, there will certainly be a problem that will cause a decline in production; therefore, it is necessary to evaluate and redesign the ESP pump, in an effort to optimize the production potential of these wells. In this study an evaluation of the performance of the electrical submersible pump will be carried out along with a pump redesign to optimize production using AutographPC software on well $X$ in field $Y$
\end{abstract}

Keywords: AutographPC, electric submersible pump, production rate

\begin{abstract}
ABSTRAK
Kondisi suatu sumur jika diproduksikan terus-menerus akan mengakibatkan tekanan reservoir turun, dan laju alir akan turun pula, akibatnya produktivitas sumur akan turun juga. Untuk itu perlu adanya tenaga yang dapat membantu mengangkat fluida sampai kepermukaan. Dalam metode primer terdapat 2 tahapan produksi yaitu natural flow dimana minyak terangkat kepermukaan langsung melalu tubing, dan artificial lift merupakan metode perolehan minyak dengan
\end{abstract}


menggunakan bantuan alat tambahan. Dalam dunia perminyakan ada berbagai macam jenis pengangkatan buatan salah satunya adalah electric submersible pump (ESP). Electric Submersibel Pump merupakan pompa listrik yang dibenamkan kedalam cairan. Pompa ini dibuat atas dasar pompa sentrifugal bertingkat banyak dimana setiap tingkat mempunyai impeller dan diffuser yang bertujuan untuk mendorong fluida kepermukaan. Perencanaan ESP sangat dipengaruhi oleh produktivitas sumur produksi. Laju produksi fluida berpengaruh terhadap pemilihan jenis dan ukuran pompa. Hal ini dikarenakan tiap-tiap pompa memiliki laju produksi sendiri berdasarkan jenis dan ukuran tiap-tiap pompa yang dipakai. Dalam kegiatan memproduksikan minyak tentu suatu saat akan terjadi permasalahan yang mengakibatkan menurunnya produksi, Oleh karena itu perlu dilaksanakan evaluasi dan design ulang pompa ESP, sebagai upaya untuk mengoptimalkan potensi produksi sumur-sumur tersebut. Pada penelitian ini akan dilakukan evaluasi kinerja electrical submersible pump dan melakukan desain ulang pompa untuk optimasi produksi dengan menggunakan software AutographPC pada sumur X lapangan y

Kata kunci: AutographPC, electric submersible pump, laju produksi

\section{PENDAHULUAN}

Dalam memproduksi minyak dari suatu sumur dapat dilakukan dengan dua cara yaitu, dengan Metode Sembur Alam dan Metode Pengangkatan Buatan (Artificial Lift). Metode Pengakatan Buatan (Artificial lift) digunakan apabila tekanan reservoir sudah tidak mampu lagi untuk memproduksi secara sembur alam. Salah satu metode pengangkatan buatan (Artificial Lift) adalah Electric Submersible Pump (ESP) (Jayanti et al, 2015).

Pemilihan ESP sebagai salah satu teknik pengangkatan buatan tentu saja berdasarkan pertimbangan teknis maupun ekonomis. ESP adalah pompa sentrifugal yang digerak kan oleh tenaga listrik yang terdiri dari beberapa stage (tingkatan), dimana setiap stage memiliki satu diffuser dan impeller yang dipasangkan pada suatu shaft. (Maulana, 2015)

Perencanaan ESP sangat dipengaruhi oleh produktivitas sumur dan sifat fluida yang dipengaruhi oleh kelakuan reservoir dari sumur tersebut (tekanan reservoir, GOR, dan water cut). Laju produksi fluida berpengaruh terhadap pemilihan jenis dan ukuran pompa. Hal ini dikarenakan tiap-tiap pompa memiliki laju produksi sendiri berdasarkan jenis dan ukuran tiap-tiap pompa yang dipakai. Namun seiring berjalannya waktu, Memproduksikan minyak pada lapangan tidak terlepas dengan adanya penurunan tekanan reservoir sehingga terjadinya penurunan rate produksi, penurunan working fluid level terhadap setting depth pompa, dan juga dapat menyebabkan adanya penurunan efisiensi volumetris pompa. (Wicaksana, 2011)

Pada penelitian ini, penulis akan mengevaluasi pompa terpasang dan mengoptimasi dengan analisa menggunakan Variable Speed Drive (VSD) dengan Speed Mode. Karena motor pompa submersible adalah sebuah induction motor, kecepatannya sangat proporsional dengan power supply listrik. Dengan mengatur 
frekuensi Variable Speed Drive, dapat mengoperasikan lebih luas kisaran dari kapasitas, head dan efisiensi sehingga dapat menentukan harga laju produksi optimum yang diinginkan. Sehingga laju produksi yang diinginkan tetap dapat dicapai tanpa harus melakukan pengerjaan penggantian pompa yang memerlukan waktu pengerjaan yang lebih lama dan biaya yang lebih besar. Kemudian mengevaluasi peralatan pendukung, seperti: Protector, kebutuhan HP, volt dan ampere motor, pemilihan kabel listrik, KVA Transformer yang dibutuhkan dan Variable Speed Drive (VSD).

\section{Data Sumur X Lapangan Y}

Tabel 1 Data reservoir

\begin{tabular}{ccc}
\hline Parameter & Nilai & Satuan \\
\hline API & 35 & \\
SG Water & 1.003 & \\
SG Gas & 0.833 & \\
ProdGOR & 35 & \\
Bubble Point & 105 & Psi \\
Pressure & & F \\
BHT & 180 & \\
\hline
\end{tabular}

Tabel 2. Data Sumur

\begin{tabular}{ccc}
\hline Parameter & Nilai & Satuan \\
\hline $\begin{array}{c}\text { Kedalaman } \\
\text { sumur }\end{array}$ & 1835 & $\mathrm{Ft}$ \\
Perforasi & 1502 & $\mathrm{Ft}$ \\
CasingID & 6.366 & $\mathrm{Inch}$ \\
Tubing & 150 & Psi \\
Pressure & & \\
\hline
\end{tabular}

Tabel 3. Data produksi

\begin{tabular}{ccc}
\hline \multicolumn{1}{c}{ Parameter } & Nilai & Satuan \\
\hline $\begin{array}{c}\text { Laju Alir } \\
\text { Fluida }\end{array}$ & 2908 & BPD \\
$\begin{array}{c}\text { Laju Alir } \\
\text { Minyak } \\
\text { (Qo) }\end{array}$ & 744,8 & BOPD \\
\hline
\end{tabular}

\begin{tabular}{ccc}
\hline Laju Alir & 2163,2 & BWPD \\
Air (Qw) & & $\%$ \\
Water Cut & 74,39 & $\%$ \\
Tubing ID & 2.992 & Inch \\
Wellhead & 103 & Psi \\
Pressure & 772 & Ft \\
SFL & 972 & Ft \\
WFL & & \\
\hline
\end{tabular}

Tabel 4. Data Pompa

\begin{tabular}{ccc}
\hline Parameter & Nilai & Satuan \\
\hline Tipe Pompa & P23SND & \\
Frekuensi & 60 & $\mathrm{~Hz}$ \\
Stages & 38 & Stages \\
Range capacity & $1200-$ & $\mathrm{BPD}$ \\
Pump Setting & 2900 & \\
Depth & 1470 & $\mathrm{Ft}$ \\
Series Motor & $562 \mathrm{SP}$ & \\
& $75 \mathrm{HP}$ & \\
Model & $1030 \mathrm{Volt}$ & \\
& 45 & \\
Ampere & \\
Series Seal & 513 & \\
Type Cable & \#AWG1 & \\
Transformer & 100 & KVA \\
VSD & 163 & KVA \\
\hline
\end{tabular}

Tujuan dari penelitian yang dilakukan adalah sebagai berikut :

1. Mengevaluasi penggunaan pompa ESP yang saat ini terpasang pada sumur kajian, Sehingga dapat diketahui apakah kapasitas pompa yang terpasang sudah sesuai dengan laju alir yang dihasilkan dan produktifitas formasi sumur tersebut.

2. Melakukan optimasi dengan mengunakan Variable Speed Drive (VSD) dengan frekuensi diatas $60 \mathrm{~Hz}$ sebagai alternative untuk meningkatkan 
performance sumur tanpa harus melakukan penggantian pompa.

3. Melakukan perbandingan hasil desain ESP antara software AutographPC dan perhitungan manual yang dilakukan.

\section{METODE PENELITIAN}

Metode penelitian yang digunakan adalah studi literatur yang berhubungan dengan perhitungan Electric Submesible pump terpasang dan melakukan observasi lapangan sehingga didapatkan data primer serta data sekunder. Kemudian dilakukan analisa pengaruh perubahan frequensi motor mengunakan simulasi dengan simulator AutographPC yang kemudian kami bandingkan dengan perhitungan manual menggunakan rumus yang sesuai. Dari hasil tersebut maka dapat ditentukan frequensi maksimum untuk pompa ESP terpasang sehingga mendapatkan rate maksimum yang diinginkan.

\section{Flow Chart}

Tahapan penelitian dapat ditampilkan dalam bentuk flow chart pada gambar 1 berikut:

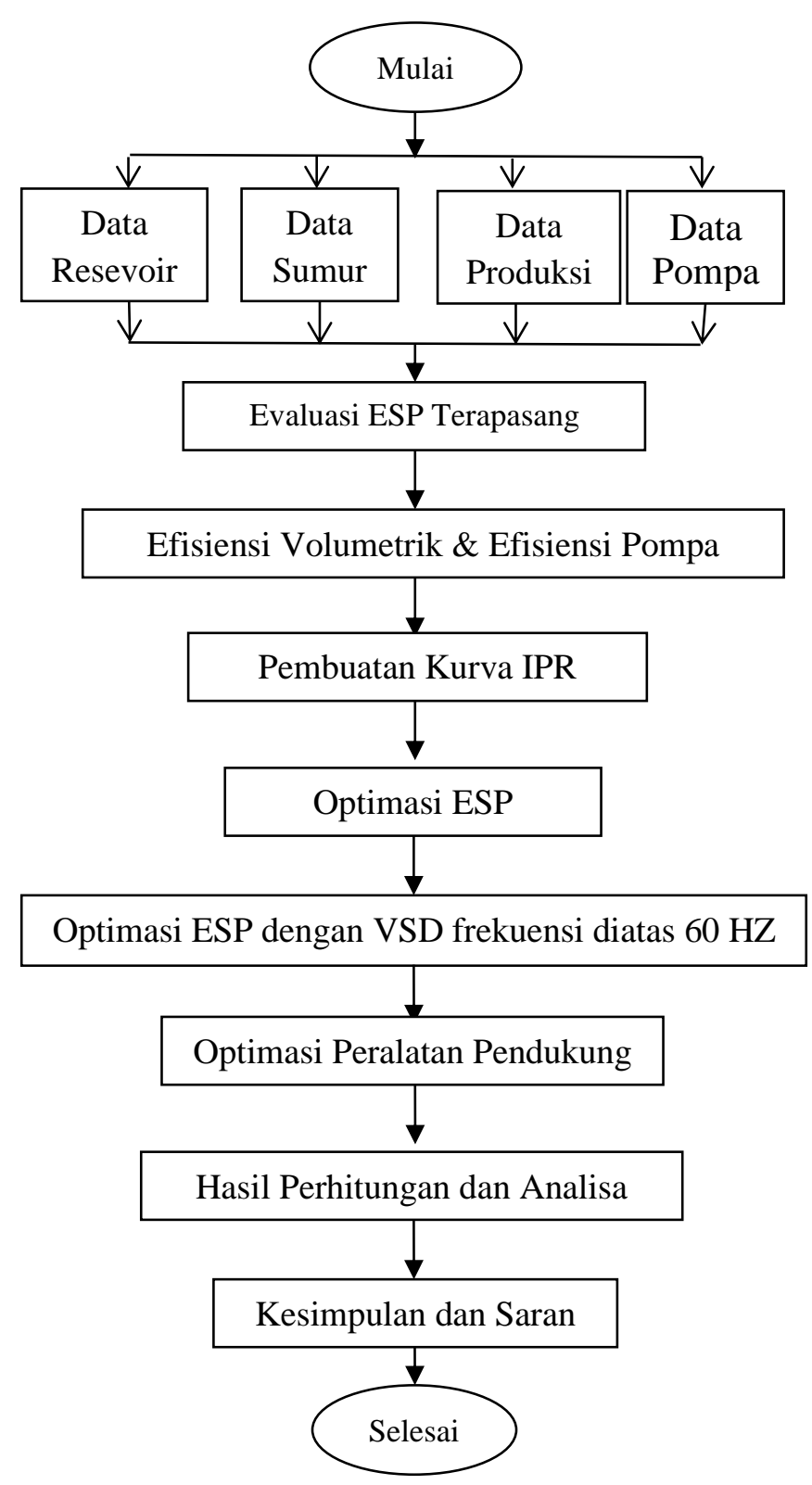

Gambar 1. Flow chart penelitian

HASIL DAN PEMBAHASAN

\section{Hasil Perhitungan Kinerja dan Evaluasi ESP Terpasang}

Hasil dan pembahasan untuk menghitung kinerja pompa ESP terpasang pada sumur X lapangan Y yang menggunakan pompa seri P23SND dengan frequensi motor di 
$60 \mathrm{HZ}$ dan 38 Stages adalah sebagai berikut pada tabel 5 :

Tabel 5 Spesifikasi pompa

\begin{tabular}{cc}
\hline Pompa & \\
Terpasang & P23SND \\
\hline Frekuensi & $60 \mathrm{~Hz}$ \\
Jumlah Stages & $38 \mathrm{stages}$ \\
Total Dynamic & $1370,359 \mathrm{Ft}$ \\
$\quad$ Head & \\
Head / stages & $36 \mathrm{ft} / \mathrm{stages}$ \\
\hline
\end{tabular}

Setelah di dapat nilai head/stages pompa terpasang kemudian dilakukan evaluasi kinerja pompa dengan mengunakan grafik pump performance curve untuk pompa P23SND sebagai berikut:

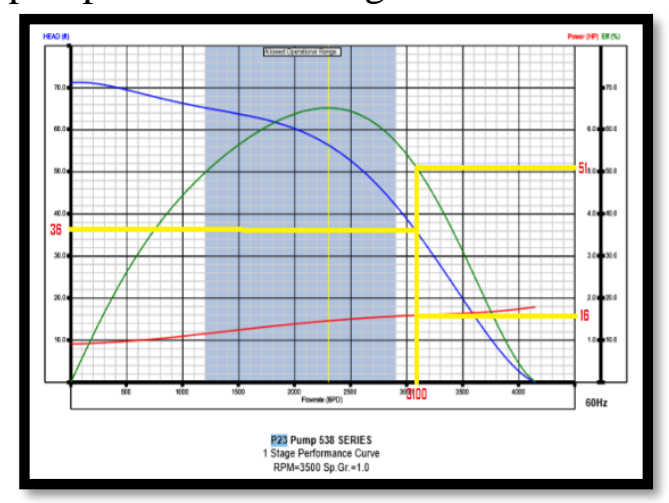

Gambar 2. Performa pompa P23SND

Dari gambar diatas, dengan memplotkan nilai Head/ stages yaitu $36 \mathrm{ft}$ di dapat data sebagai berikut :

- Qactual = 2908 BFPD

- Qteori = 3100 BFPD

- Effisiensi pompa $=51 \%$

- Effisiensi volumeris $=93,8$ $\%$

\section{Penentuan Produktifitas Formasi}

Sebelum melakukan perubahan frekuensi pompa menggunakan Variable Speed Drive pada pompa ESP, terlebih dahulu menentukan produktifitas formasi yang dapat di sajikan dalam bentuk kurva IPR.

Sesuai dengan data yang tersedia, bahwa tekanan static lebih besar dari tekanan jenuh atau (Ps $>\mathrm{Pb}$ ) dan $\mathrm{Pwf}$ $>\mathrm{Pb})$ maka pembuatan kurva IPR dilakukan dengan metode 1 fasa dan 2 fasa. Maka didapati kurva IPR sebagai berikut :

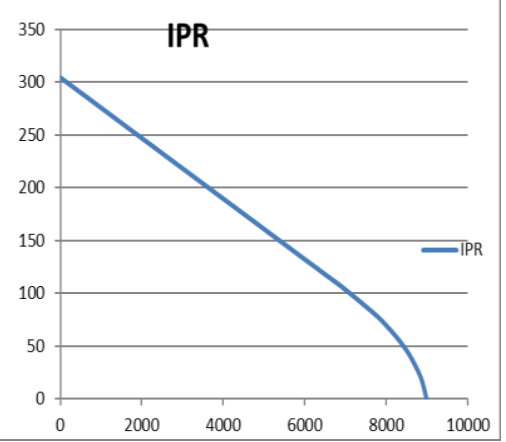

Gambar 3. Kurva IPR

\section{Optimasi ESP menggunakan} Variasi Frequensi secara hitungan manual

Pengoptimasian pompa ESP berikut dilakukan pada pompa terpasang pada sumur " $\mathrm{X}$ " yaitu pompa series P23SND dengan merubah frekuensi putaran pompa hingga diatas $60 \mathrm{~Hz}$ dengan menggunakan VSD.

\section{Penentuan head dan motor load \\ Penentuan Head dan Motor Load pada pompa P23 menggunakan Pump Performance Curve pada gambar 4 di bawah ini.}




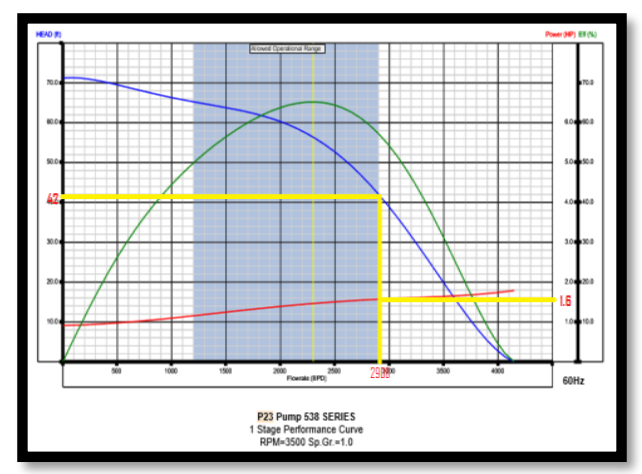

Gambar 4. Head and motor load dengan memplot laju produksi actual $(\mathrm{Qt}=2908$ BFPD) di dapat data sebagai berikut :

- Head $=42 \mathrm{ft} /$ stages Head total = $42 \times 38=1596 \mathrm{ft}$

- $\quad$ Motor Load = 1.6 HP/stages

- Motor Load total $=1,6 \times 38=$ 60,8 HP

2. Penentuan Rate, Head, dan Motor Load dengan Frekuensi Baru

Dengan merubah frekuensi pada VSD maka flowrate, Head, dan Motor Load juga akan berubah, besarnya perubahan flowrate, Head, dan Motor Load dapat di ketahui menggunakan persamaan affinity Law.

Pada Pompa P23SND di sumur " $X$ " memiliki frekuensi $60 \mathrm{~Hz}$ dengan Flowrate 2908 BFPD, Head 1596 ft, dan Motor Load 60,8 HP. Contoh pertama dengan menaikan Frekuensi menjadi $63 \mathrm{~Hz}$, Maka :

- Rate $63 \mathrm{~Hz}=(63 \mathrm{~Hz}) /(60 \mathrm{~Hz}) \mathrm{x}$ 2908 BFPD $=3053,4$ BFPD

- Head $63 \mathrm{~Hz}=(63 / 60)^{\wedge} 2 \times 1596$ $\mathrm{ft}=1759,59 \mathrm{ft}$

- $\quad$ Motor Load $63 \mathrm{~Hz}=(63 / 60)^{\wedge} 3$ x $60,8 \mathrm{HP}=70,384 \mathrm{HP}$
Berikut tabel 6 Rate, Head, dan motor load, untuk setiap perubahan Frekuensi.

Tabel 6. Rate, head and motor load

\begin{tabular}{|c|c|c|c|c|}
\hline $\begin{array}{c}\text { Freku } \\
\text { ensi } \\
(\mathrm{Hz})\end{array}$ & $\begin{array}{c}\text { Rate } \\
\text { (BPD } \\
\text { ) }\end{array}$ & $\begin{array}{c}\text { Head } \\
\text { (ft) }\end{array}$ & $\begin{array}{c}\text { Mot } \\
\text { or } \\
\text { Loa } \\
\text { d } \\
\text { (HP } \\
\text { ) } \\
\end{array}$ & $\begin{array}{c}\text { Rate } \\
\text { Oil }\end{array}$ \\
\hline 60 & 2908 & 1596 & 60.8 & $\begin{array}{c}744.7 \\
388\end{array}$ \\
\hline 61 & $\begin{array}{c}2956 . \\
467\end{array}$ & $\begin{array}{c}1649 . \\
643\end{array}$ & $\begin{array}{c}63.8 \\
91\end{array}$ & $\begin{array}{c}757.1 \\
511\end{array}$ \\
\hline 62 & $\begin{array}{c}3004 . \\
933\end{array}$ & $\begin{array}{c}1704 \\
173\end{array}$ & $\begin{array}{c}67.0 \\
85\end{array}$ & $\begin{array}{c}769.5 \\
634\end{array}$ \\
\hline 63 & $\begin{array}{c}3053 . \\
4\end{array}$ & $\begin{array}{c}1759 . \\
59\end{array}$ & $\begin{array}{c}70.3 \\
84\end{array}$ & $\begin{array}{c}781.9 \\
757\end{array}$ \\
\hline 64 & $\begin{array}{c}3101 . \\
867\end{array}$ & $\begin{array}{c}1815 \\
893\end{array}$ & $\begin{array}{c}73.7 \\
89\end{array}$ & $\begin{array}{c}794.3 \\
881\end{array}$ \\
\hline 65 & $\begin{array}{c}3150 . \\
333\end{array}$ & $\begin{array}{c}1873 . \\
083\end{array}$ & $\begin{array}{c}77.3 \\
02\end{array}$ & $\begin{array}{c}806.8 \\
004\end{array}$ \\
\hline 66 & $\begin{array}{c}3198 . \\
8\end{array}$ & $\begin{array}{c}1931 . \\
16\end{array}$ & $\begin{array}{c}80.9 \\
25\end{array}$ & $\begin{array}{c}819.2 \\
127\end{array}$ \\
\hline 67 & $\begin{array}{c}3247 . \\
267\end{array}$ & $\begin{array}{c}1990 . \\
123\end{array}$ & $\begin{array}{c}84.6 \\
59\end{array}$ & $\begin{array}{c}831.6 \\
25\end{array}$ \\
\hline 68 & $\begin{array}{c}3295 . \\
733\end{array}$ & $\begin{array}{c}2049 . \\
973\end{array}$ & $\begin{array}{c}88.5 \\
07\end{array}$ & $\begin{array}{c}844.0 \\
373\end{array}$ \\
\hline 69 & $\begin{array}{c}3344 . \\
2\end{array}$ & $\begin{array}{c}2110 . \\
71\end{array}$ & $\begin{array}{c}92.4 \\
69\end{array}$ & $\begin{array}{c}856.4 \\
496\end{array}$ \\
\hline 70 & $\begin{array}{c}3392 . \\
667 \\
\end{array}$ & $\begin{array}{c}2172 . \\
333 \\
\end{array}$ & $\begin{array}{c}96.5 \\
48 \\
\end{array}$ & $\begin{array}{c}868.8 \\
619 \\
\end{array}$ \\
\hline
\end{tabular}

\section{Evaluasi Ukuran Komponen @63 Hz}

a. Pump Setting Depth (PSD)

Dalam optimasi menggunakan metode frekuensi up menggunakan VSD, Pump Setting Dept tidak dilakukan perubahan, tetap seperti PSD keadaan awal yaitu $1470 \mathrm{ft}$.

b. Protector (Seal Section)

Protector yang dipilih saat ini adalah protector Series 513. Pada protector ini membutuhkan HP sebesar 2.82 HP berdasarkan Kurva HP versus TDH $1759,59 \mathrm{ft}$ 
@ $63 \mathrm{~Hz}$ yang dapat dilihat pada gambar 5 dibawah.

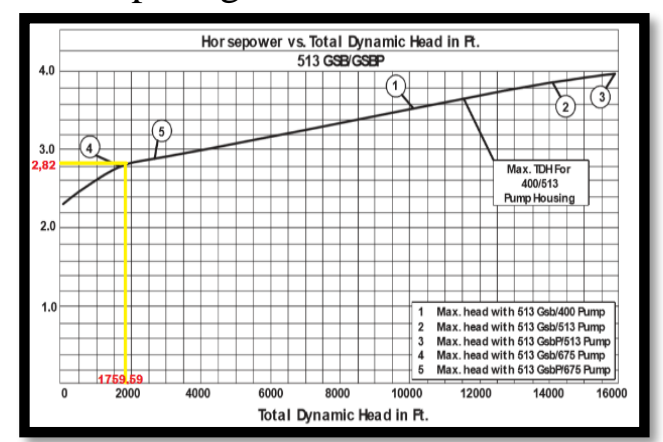

Gambar 5. Horsepower vs total dynamic head

Jadi total HP yang dibutuhkan : Total HP= Motor Load (@63 $\mathrm{Hz})+$ Seal Section HP

$$
\begin{aligned}
& =70,384+2,82 \\
& =73,204 \mathrm{HP}
\end{aligned}
$$

\section{c. Jenis Motor}

Jenis Motor yang terpasang adalah Series 562SP_ 75 HP 1030 Volt 45 Ampere, sehingga ampere total yang dibutuhkan :

Ampere @ 73,204= (HP total) / (HP motor) $\mathrm{x}$ ampere motor

$=(73.204 \mathrm{HP}) /(75 \mathrm{HP}) \times 45$ ampere $=43,92$ ampere

\section{d. Kabel Listrik}

Pemilihan ukuran kabel berdasarkan kemampuan dari arus pembawanya. Pilih ukuran kabel dengan voltage drop kurang dari 30 volt per $1000 \mathrm{ft}$. dalam kasus ini kabel yang di pilih pada pompa esp adalah kabel \#1 AWG. Motor ampere sebesar 43,92 ampere di plot pada grafik voltage drop pada Gambar 6, maka di dapat voltage drop @ $180^{\circ} \mathrm{f}$ sebesar 10,135 volt/1000 ft.

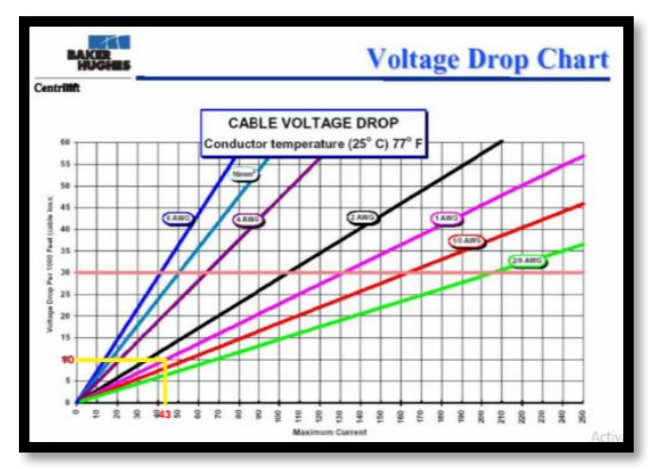

Gambar 6. Voltage chart

Correction factor pada temperature $180{ }^{\circ} \mathrm{f}$ ditunjukan pada tabel 7 dibawah ini setelah dilakukan interpolasi didapat hasil sebesar 1,2189 .

\begin{tabular}{|c|c|c|c|c|c|c|c|c|}
\hline \multicolumn{9}{|c|}{$\begin{array}{l}\text { CONDUCTOR VOLTAGE LOSS TABLE } \\
\text { Temperature Correction Factor }{ }^{\circ} 25^{\circ} \mathrm{C}\left(77^{\circ} \mathrm{F}\right)\end{array}$} \\
\hline Temp ${ }^{\circ} \mathrm{F}$ & Temp ${ }^{\circ} \mathrm{C}$ & $\begin{array}{l}\text { Mult } \\
\text { Factor }\end{array}$ & Temp ${ }^{\circ} \mathrm{F}$ & Temp ${ }^{\circ} \mathrm{C}$ & $\begin{array}{l}\text { Mult. } \\
\text { Factor }\end{array}$ & Temp ${ }^{\circ} \mathrm{F}$ & Temp ${ }^{\circ} \mathrm{C}$ & $\begin{array}{l}\text { Mult } \\
\text { Factor }\end{array}$ \\
\hline 50 & 10 & 0.94 & 221 & 105 & 1.31 & 392 & 200 & 1.67 \\
\hline 59 & 15 & 0.96 & 230 & 110 & 1.33 & 401 & 205 & 1.69 \\
\hline 68 & 20 & 0.98 & 239 & 115 & 1.35 & 410 & 210 & 1.71 \\
\hline 77 & 25 & 1.00 & 248 & 120 & 1.37 & 419 & 215 & 1.73 \\
\hline 86 & 30 & 1.02 & 257 & 125 & 1.39 & 428 & 220 & 1.75 \\
\hline 95 & 35 & 1.04 & 266 & 130 & 1.40 & 437 & 225 & 1.77 \\
\hline 104 & 40 & 1.06 & 275 & 135 & 1.42 & 446 & 230 & 1.79 \\
\hline 113 & 45 & 1.08 & 284 & 140 & 1.44 & 455 & 235 & 1.81 \\
\hline 122 & 50 & 1.10 & 293 & 145 & 1.46 & 464 & 240 & 1.83 \\
\hline 131 & 55 & 1.12 & 302 & 150 & 1.48 & 473 & 245 & 1.85 \\
\hline 140 & 60 & 1.13 & 311 & 155 & 1.50 & 482 & 250 & 1.87 \\
\hline 149 & 65 & 1.15 & 320 & 160 & 1.52 & 491 & 255 & 1.89 \\
\hline 158 & 70 & 1.17 & 329 & 165 & 1.54 & 500 & 260 & 1.91 \\
\hline 167 & 75 & 1.19 & 338 & 170 & 1.56 & 509 & 265 & 1.92 \\
\hline 176 & 80 & 1.21 & 347 & 175 & 1.58 & 518 & 270 & 1.94 \\
\hline 185 & 85 & 1.23 & 356 & 180 & 1.60 & 527 & 275 & 1.96 \\
\hline 194 & 90 & 1.25 & 365 & 185 & 1.62 & 536 & 280 & 1.98 \\
\hline 203 & 95 & 1.27 & 374 & 190 & 1.64 & 545 & 285 & 2.00 \\
\hline 212 & 100 & 1.29 & 383 & 195 & 1.65 & 554 & 290 & 2.02 \\
\hline
\end{tabular}

Tabel 7. Conductor voltage loss

Voltage Drop dapat di hitung sebagai berikut:

Panjang kabel yang di butuhkan

$$
\begin{aligned}
& =\mathrm{PSD}+100 \mathrm{ft} \\
& =1470+100 \mathrm{ft} \\
& =1570 \mathrm{ft}
\end{aligned}
$$

Volt drop $=$ (volt.drop @ $180^{\circ} \mathrm{f} x$

Panjang Kabel x corr.factor)/1000

$=(10,135 \times 1570 \times 1,2189) / 1000$

$=19,5$ volt

\section{e. Transformer dan Variable Speed Drive}

Dalam mengevaluasi transformer, harus dihitung surface voltage dan total KVA terlebih dahulu. 
- Surface Voltage $=$ Motor Voltage $\mathrm{x}(($ Frekuensi $\quad$ Baru $) /(60$ $\mathrm{Hz})+$ +Voltage Drop $=1030$ volt $\mathrm{x}(63 \mathrm{~Hz}) /(60 \mathrm{~Hz})+19,5$ $=1101$ volt

- $\mathrm{KVA}=($ Surface Voltage $\mathrm{x}$ Motor ampere x 1,73)/1000

$=(1101 \times 45 \times 1,73) / 1000$

$=85,71 \mathrm{KVA}$

Sedangkan Transformer yang terpasang adalah transformer dengan kapasitas 100 KVA, kapasitas transformer ini masih lebih besar dari KVA total yang dibutuhkan yaitu $85,68 \mathrm{KVA}$ sehingga masih dapat di gunakan.

Sementara itu VSD yang terpasang adalah VSD dengan kapasitas 163 KVA, kapasitas VSD ini masih lebih besar dari KVA total yang dibutuhkan yaitu 85,68 KVA sehingga masih dapat di gunakan.

Berikut dapat di sajikan pada lampiran1 tabel sensitifitas anaitis mengunakan perhitungan manual dengan rumus yang sesuai untuk setiap perubahan frequensi pompa.

\section{Optimasi menggunakan software AutographPC}

Proses design ESP menggunakan software autographPC dilakukan dengan memasukan data well, pump, motor, seal, cable, dan controller. Sesuai dengan data yang kita miliki pada sumur $\mathrm{X}$, kemudian dalam melakukan optimasi dengan menggunakan metode frekuensi up dalam AutographPC terdapat tool yang dapat digunakan untuk menampilkan perhitungan sensitivity analitis sumur.

Sensitivity analitis hasil perhitungan software autographPC ditampilkan dalam Tabel pada Lampiran 2

\section{Perbandingan hasil optimasi menggunakan hitungan manual dan Software AutographPC dengan hasil real data lapangan.}

Dari data sensitivity analitis kedua metode terdapat perbedaan nilai sebagai contohnya pada $63 \mathrm{~Hz}$ menggunakan perhitungan manual laju alir fluida menunjukan nilai 3053,4 BPD dan menggunakan software autographPC laju alir fluida menunjukan nilai 3135 BPD, kami juga sajikan perbandingan sensitifity analitis kedua metode dalam bentuk grafik yang dapat dilihat di Lampiran 3.

$\begin{array}{lr}\text { Sebagai pembuktian } & \text { metode } \\ \text { yang paling mendekati } & \text { dalam } \\ \text { perkiraan keadaan sumur setelah } \\ \text { peningkatan frekuensi r maka } \\ \text { dilakukan frekuensi up pada sumur X } \\ \text { ke frekuensi } 63 \mathrm{~Hz} \text { dan kemudian laju } \\ \text { alir fluida yang didapat adalah sebesar } \\ \text { 3139,92 BPD. }\end{array}$

Dari data diatas dapat ditarik kesimpulan bahwa hasil sensitivity analitis yang paling mendekati dengan keadaan actual adalah sensitivity analitis menggunakan software autographPC

\section{KESIMPULAN DAN SARAN}

\section{Kesimpulan}

1. Evaluasi pompa ESP dilakukan dengan menggunakan data pump performance curve untuk pompa P23 kemudian memplotkan nilai head/stages sehingga didapat Qteori $=$ 3100 BFPD dengan Qactual = 2908 BFPD, Effisiensi pompa $=50 \%$, dan Effisiensi Volumetris $=93,8 \%$ dari data 
ini diketahui bahwa pompa dalam Upthrust kondisi.

2. Optimasi pompa ESP dilakukan dengan menggunakan Variable Speed Drive (VSD) pada frekuensi awal $60 \mathrm{~Hz}$ dengan laju produksi 2908 BFPD. Kemudian frekuensi dinaikan menjadi $63 \mathrm{~Hz}$, pada perhitungan manual laju produksi yang didapat adalah 3035,4 BFPD sedangkan pada perhitungan software AutographPC laju produksi yang didapat adalah 3151 BFPD.

3. Setelah dilakukan optimasi mengunakan VSD dengan menaikan frekuensi ke $63 \mathrm{~Hz}$ maka didapatkan hasil dengan menggunakan perhitungan manual yaitu 3035,4 BFPD dan $3153 \quad$ BFPD menggunakan perhitungan AutographPC sementara itu setelah diaplikasikan ke sumur kajian menghasilkan laju alir fluida sebesar 3139,92 BFPD. Dapat ditarik kesimpulan bahwa metode paling mendekati dengan keadaan pegaplikasian dilapangan adalah dengan mengunakan perhitungan software AutographPC

\section{Saran}

Kepada peneliti berikutnya, saran yang penulis dapat berikan adalah ;

1. Pada saat melakukan optimasi pada pompa ESP agar dapat menghitung besaran pengaruh peningkatan rate dengan peningkatan watercut yang kemudian berhubungan dengan usia sumur dapat diproduksikan

2. Diharapkan setiap design awal pompa ESP sebaiknya selalu mengunakan alat downhole sensor, agar dapat lebih akurat dalam medapatkan data yang di perlukan kemudian.

\section{DAFTAR PUSTAKA}

Brown, KE. 1980. The Technology of Artificial Lift Methods. Volume 1. The University of Tulsa, Petroleum Publishing Co. Tulsa

Jayanti, P.D., Sudibyo, R. dan Sulustiyanto, D. 2015. Evaluasi dan Optimasi Pompa Electric submersible Pump (ESP) Pada SumurSumur Di Lapangan X.Seminar Nasional Cendekiawan.

Marpaung, C.A. 2015. Optimasi Penggunaan Electric submersible pump pada Sumur RN dan NM di Lapangan Y Seminar Nasional Cendekiawan.

Maulana, R. 2015. Evaluasi, Optimasi, dan Keekonomian Elelctric Submersible Pump (ESP) untuk Sumur RA dan DR di Lapangan Z PERTAMINA HULU ENERGI OFFSHORE NORTH WEST JAVA.Seminar Cendikiawan.

Wicaksana, S. 2011. Evaluasi dan Perencanaan Ulang Electrik Submersible Pump (ESP) pada Sumur " $X$ " Lapangan "Y".Yogyakarta. 
Lampiran 1 Tabel Sensitivity Hitungan Manual

\begin{tabular}{ccccccccccc}
\hline $\begin{array}{c}\text { Freq } \\
(\mathbf{H z})\end{array}$ & $\begin{array}{c}\text { Flow } \\
(\mathbf{B P D})\end{array}$ & TDH (ft) & $\begin{array}{c}\text { BHP } \\
(\mathbf{H P})\end{array}$ & $\begin{array}{c}\text { Mshp } \\
\mathbf{6 0} \\
(\mathbf{H P})\end{array}$ & $\begin{array}{c}\text { Mtr } \\
\text { Load } \\
(\mathbf{\%})\end{array}$ & $\begin{array}{c}\text { MtrV } \\
(\mathbf{V})\end{array}$ & $\begin{array}{c}\text { MtrA } \\
(\mathbf{A})\end{array}$ & $\begin{array}{c}\text { Surf } \\
\text { KVA } \\
(\text { KVA) }\end{array}$ & $\begin{array}{c}\text { SurfV } \\
(\mathbf{V})\end{array}$ & $\begin{array}{c}\text { Qoil } \\
(\mathbf{B P D})\end{array}$ \\
\hline $\mathbf{6 0}$ & 2908 & 1596 & 60.8 & 63.5611 & 84.748 & 1030 & 38.137 & 80.871 & 1038.801 & 744.7388 \\
$\mathbf{6 1}$ & 2956.467 & 1649.643 & 63.891 & 66.6676 & 88.89 & 1047.17 & 40.001 & 82.241 & 1056.398 & 757.1511 \\
$\mathbf{6 2}$ & 3004.933 & 1704.173 & 67.085 & 69.8773 & 93.17 & 1064.33 & 41.926 & 83.612 & 1074.009 & 769.5634 \\
$\mathbf{6 3}$ & 3053.4 & 1759.59 & 70.384 & 73.204 & 97.605 & 1081.5 & 43.922 & 85.713 & 1101.008 & 781.9757 \\
$\mathbf{6 4}$ & 3101.867 & 1815.893 & 73.789 & 76.6104 & 102.15 & 1098.67 & 45.966 & 87.121 & 1119.082 & 794.3881 \\
$\mathbf{6 5}$ & 3150.333 & 1873.083 & 77.302 & 80.1283 & 106.84 & 1115.83 & 48.077 & 88.53 & 1137.187 & 806.8004 \\
$\mathbf{6 6}$ & 3198.8 & 1931.16 & 80.925 & 83.7563 & 111.68 & 1133 & 50.254 & 89.942 & 1155.32 & 819.2127 \\
$\mathbf{6 7}$ & 3247.267 & 1990.123 & 84.659 & 87.4953 & 116.66 & 1150.17 & 52.497 & 91.356 & 1173.483 & 831.625 \\
$\mathbf{6 8}$ & 3295.733 & 2049.973 & 88.507 & 91.3485 & 121.8 & 1167.33 & 54.809 & 92.772 & 1191.677 & 844.0373 \\
$\mathbf{6 9}$ & 3344.2 & 2110.71 & 92.469 & 95.3157 & 127.09 & 1184.5 & 57.189 & 94.191 & 1209.901 & 856.4496 \\
$\mathbf{7 0}$ & 3392.667 & 2172.333 & 96.548 & 99.4 & 132.53 & 1201.67 & 59.64 & 95.612 & 1228.156 & 868.8619 \\
\hline
\end{tabular}


Lampiran 2 Table Sensitivity Analitis Sofware AutographPC

\begin{tabular}{cccccccccc}
\hline $\begin{array}{c}\text { Freq } \\
(\mathbf{H z})\end{array}$ & $\begin{array}{c}\text { Flow } \\
(\mathbf{B P D})\end{array}$ & $\begin{array}{c}\text { TDH } \\
(\mathbf{f t})\end{array}$ & $\begin{array}{c}\text { Mshp60 } \\
(\mathbf{H P})\end{array}$ & $\begin{array}{c}\text { Mtr } \\
\text { Load } \\
(\mathbf{\%})\end{array}$ & $\begin{array}{c}\text { MtrV } \\
(\mathbf{V})\end{array}$ & $\begin{array}{c}\text { MtrA } \\
(\mathbf{A})\end{array}$ & $\begin{array}{c}\text { Surf } \\
\text { KVA } \\
(\mathbf{K V A})\end{array}$ & $\begin{array}{c}\text { SurfV } \\
(\mathbf{V})\end{array}$ & $\begin{array}{c}\text { Qoil } \\
(\mathbf{B P D})\end{array}$ \\
\hline $\mathbf{6 0}$ & 2908 & 1387 & 56 & 74.67 & 961.5 & 35.84 & 60.67 & 977.4 & 744.7 \\
$\mathbf{6 1}$ & 2984 & 1389 & 57.84 & 77.12 & 984.8 & 36.74 & 63.71 & 1001 & 764.3 \\
$\mathbf{6 2}$ & 3060 & 1390 & 59.69 & 79.59 & 1008 & 37.65 & 66.85 & 1025 & 783.6 \\
$\mathbf{6 3}$ & 3135 & 1390 & 61.56 & 82.08 & 1032 & 38.57 & 70.09 & 1049 & 802.8 \\
$\mathbf{6 4}$ & 3209 & 1390 & 63.45 & 84.6 & 1056 & 39.49 & 73.42 & 1073 & 821.8 \\
$\mathbf{6 5}$ & 3283 & 1390 & 65.35 & 87.13 & 1080 & 40.41 & 76.84 & 1098 & 840.7 \\
\hline
\end{tabular}

Lampiran 3 Grafik Perbandingan Sensitivity analisis Hitungan manual dan AutographPC

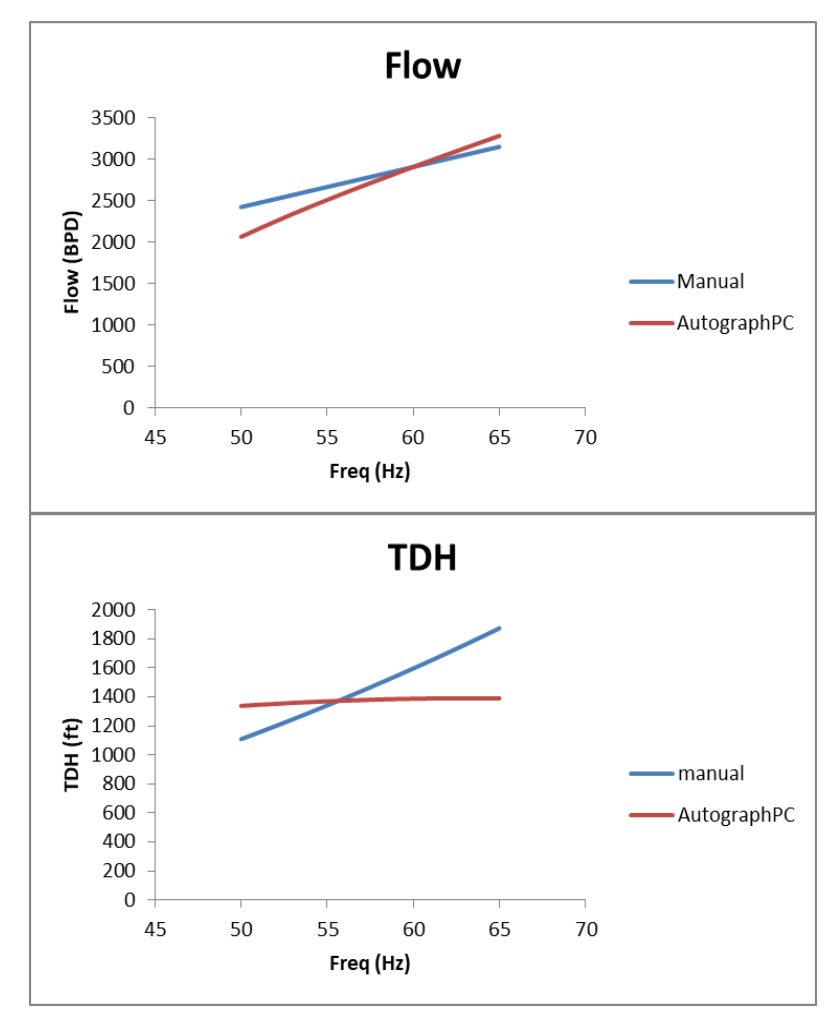




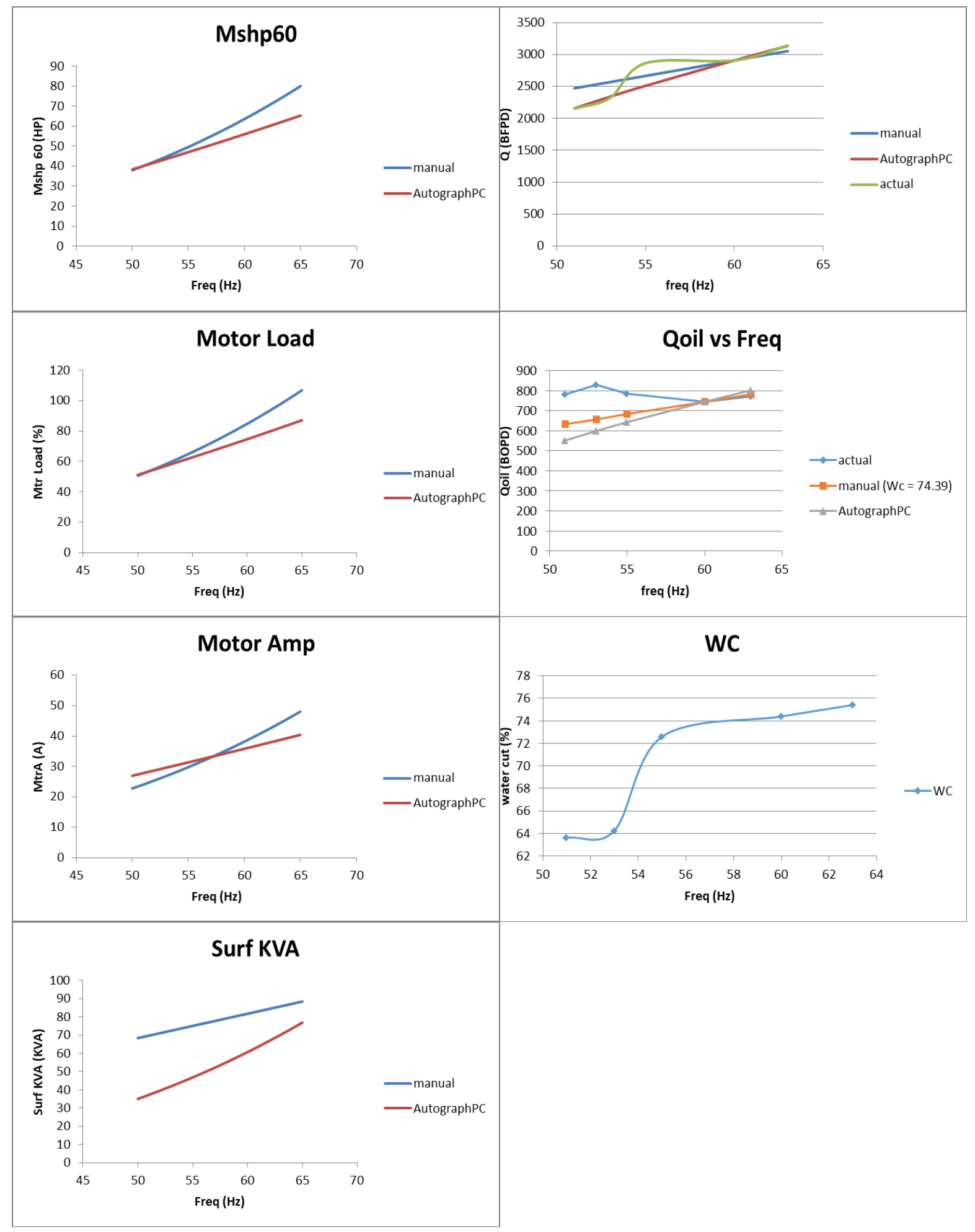

